\title{
Enhancing the Supersonic Wind Tunnel Performance Based on Plenum Temperature Control
}

\author{
A. Nazarian Shahrbabaki, M. Bazazzadeh, A. Shahriari, and M. Dehghan Manshadi \\ Department of Mechanical \& Aerospace Engineering, Malek-Ashtar University of Technology, \\ Shahin Shahr, Isfahan 83145/115, Iran
}

Correspondence should be addressed to A. Nazarian shahrbabaki; a.n.shahrbabaki@gmail.com

Received 9 February 2014; Accepted 4 March 2014; Published 2 April 2014

Academic Editors: E. J. Avital and Y. Shi

Copyright (C) 2014 A. Nazarian shahrbabaki et al. This is an open access article distributed under the Creative Commons Attribution License, which permits unrestricted use, distribution, and reproduction in any medium, provided the original work is properly cited.

The application of fuzzy logic controllers (FLCs) to the control of nonlinear processes, typically controlled by a human operator, is a topic of much study. In this paper, the design and application of a FLC is discussed to control the plenum chamber temperature for a blowdown supersonic wind tunnel (BSWT) with the aim of achieving the accurate and desired results. In this regard, first, a nonlinear mathematical model of special BSWT is developed in Matlab/Simulink software environment. Next, an artificially intelligent controller is designed using fuzzy logic approach. For this purpose, a proportional-derivative FLC (PD-FLC) system is developed in the Simulink toolbox to control the plenum stagnation temperature using a heater upstream of the plenum chamber. Finally, the system simulation results inside of the temperature and pressure controllers in comparison with the experimental run are presented. The results for Mach 2.5 blowdown run show the great performance of the Wind Tunnel Simulator Model and its temperature controller system.

\section{Introduction}

Blowdown supersonic wind tunnels (BSWTs) deliver flow at constant stagnation temperature and pressure. The stagnation temperature is generally regarded to be equal to the plenum temperature which is controlled by heater upstream of the plenum chamber. During a blowdown run, the storage tank temperature and pressure that supplies plenum chamber flow decrease continuously. Thus, to maintain a constant plenum pressure as close as possible to a setpoint pressure signal, the regulator or control valve must open progressively. Besides, to maintain a constant stagnation temperature in the plenum chamber, a heater must operate continuously during a supersonic run [1-3]. The controller must operate at different stagnation pressures and Mach numbers and has to be robust to accommodate the varying pressure and mass flow requirements safely. New concepts for control are under implementation with the goal of reducing transition phase and overall loads on the models $[4,5]$.

The block diagram of the control systems in the proposed BSWT is illustrated in Figure 1.

Fuzzy logic has been the area of heated debate and much controversy during the last decades. The first paper in fuzzy set theory, which is now considered to be the seminar paper of the subject, was written by Zadeh et al. [6], who is considered the founding father of the field. In that work, Zadeh was implicitly advancing the concept of approximate human reasoning to make effective decisions on the basis of the available imprecise, linguistic information.

In the 1970s, King and Mamdani [7] studied the application of FLCs to the control of nonlinear industrial processes that typically can only be controlled successfully by a human operator. The idea of FLCs has become a common solution in recent years, with applications ranging from automation of industrial processes to control of electronic devices in consumer products. The design and application of a FLC for the control of plenum chamber temperature in several wind tunnels at NASA's Langley Research Center (LaRC) in Hampton, VA, is described [8].

The intelligent controlling approaches like fuzzy logic (FL) will provide the required scope for wind tunnels to be more efficient, safe, and economic. The approaches will help to enable a level of performance that far exceeds that of today's wind tunnel in terms of reduction of harmful emissions, maximization of run time, and minimization of noise, while improving system affordability and safety. 


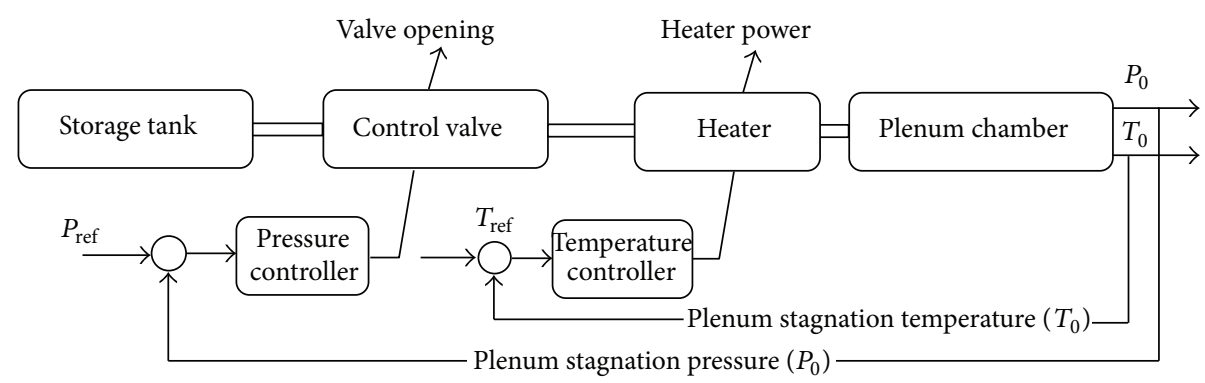

FIGURE 1: Schematic diagram of the pressure and temperature control systems in the supersonic wind tunnel.

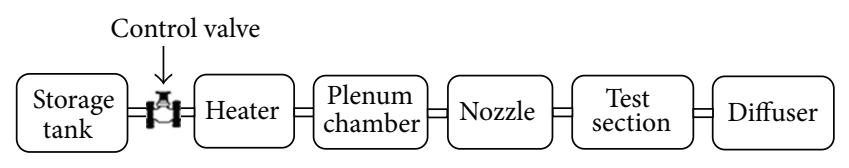

Figure 2: Schematic diagram of the blowdown supersonic wind tunnel.

In this paper, a nonlinear mathematical model of a special BSWT is developed in Simulink software simulator. Next, a PD-FLC system is developed in the Simulink toolbox to control the plenum stagnation temperature. Finally, the simulation results for a Mach 2.5 blowdown run in comparison with the experimental results are presented along.

\section{Wind Tunnel Mathematical Model}

The schematic diagram of the proposed BSWT is shown in Figure 2. In the figure, the major subsystems are a storage tank, a gate valve, a pressure regulator valve or control valve, a heater, a plenum chamber, a supersonic nozzle, a test section, a diffuser, and a silencer.

2.1. Heater. There are two ways in which BSWTs are customary operated: (1) operation with constant pressure and (2) operation with constant-mass flow rate [8].

For constant pressure operation, the only control necessary is a pressure control valve that holds the stagnation pressure constant. By the way, for constant-mass runs, the stagnation temperature must be held constant and either a heater or a thermal mass external to the storage tank is required. Even more important, the constant temperature of the constant-mass run keeps the Reynolds number constant in the test section. This drop in stagnation temperature affects the Mach number in the test section only secondarily through a change in boundary layer thickness, but it can affect balance strain gage readings significantly, and it does change the Reynolds number during a run.

Obviously a heater downstream of the storage tank could be designed to yield essentially zero temperature drops, and such heaters are sometimes employed. In this regard, the controlled flow stagnation temperature in the heater output is presented as [9]

$$
T_{H}=T_{\text {in }}+\left[\frac{W_{\text {th }}}{q_{v} C_{p}}\right],
$$

where $T_{H}$ is the flow stagnation temperature in the heater output $(\mathrm{K}), T_{\text {in }}$ is the air initial stagnation temperature $(\mathrm{K})$, $W_{\mathrm{th}}$ is the thermal input power $(W), q_{v}$ is the mass flow rate through the valve $\left(\mathrm{kg} \cdot \mathrm{s}^{-1}\right)$, and $C_{p}$ is the gas constant pressure specific heat $\left(\mathrm{J} \cdot \mathrm{kg}^{-1} \cdot \mathrm{K}^{-1}\right)$.

2.2. Control Valve. BSWTs are generally operated with a constant stagnation pressure in the plenum chamber, with control usually provided by one or more pressure control valves. In this regard, a main step of the control valve simulation is calculating the mass flow rate through the valve. This parameter is determined using the standard valve sizing relation as $[10,11]$

$$
q_{V}=C_{v} N_{8} F_{P} Y P_{T} \sqrt{\frac{\left(X M_{a}\right)}{\left(T_{T} Z\right)}} .
$$

In (2), $C_{v}$ is the valve sizing coefficient, $N_{8}$ is a constant for units, $F_{P}$ is a correction factor that accounts for pressure losses due to piping fittings and elbows, $Y$ is expansion factor, $P_{T}$ is the tank stagnation pressure, $X$ is the valve pressure drop ratio, $M_{a}$ is the air molecular weight, $T_{T}$ is the tank stagnation temperature, and $Z$ is the air compressibility factor.

It should be noted that $C_{v}$ is the functions of control valve opening and should be provided by the manufacturer of the control valve. In this paper, for the valve opening simulation during the tunnel run, some lookup tables were set to the valve manufacturer's data.

\section{Wind Tunnel Simulator Model (WTSM)}

3.1. Facility and Requirements. The tunnel has a Mach number range of 1.5 to 3, a Reynolds number range of $25 \sim 100 \times 10^{6}$ per meter, and up to 70 seconds of usable run time. Also the tunnel is operated using a 12-inch diameter, pneumatically driven automatic butterfly valve (Bray control valve). The storage tank has a volume of $220 \mathrm{~m}^{3}$ and it is filled with 


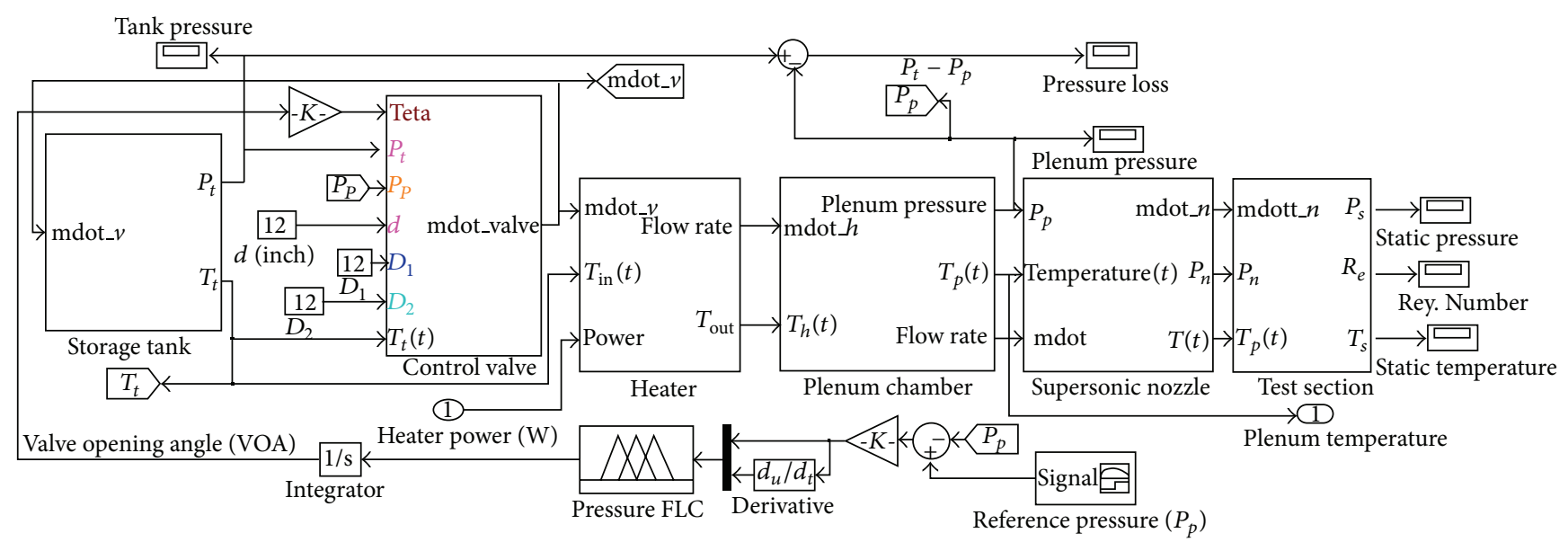

FIGURE 3: Wind tunnel simulator model and pressure controller development in Matlab/Simulink software environment.

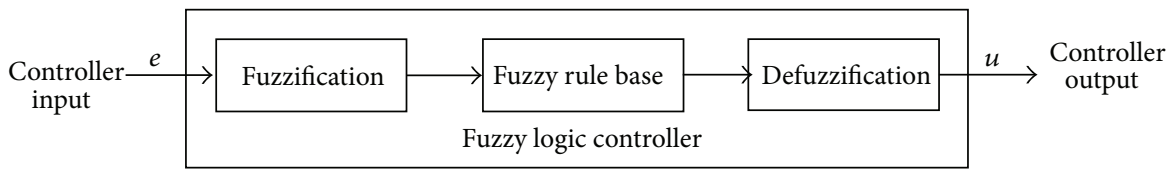

FIGURE 4: The block diagram of the fuzzy logic controller.

compressed, dry air at $1.2 \mathrm{MPa}$ before the run. The heaters for the BSWT system are electric heaters requiring threephase AC voltage input which is controlled by a silicon controlled rectifier (SCR). The air flowing into the heaters passes through a bundle of electrical resistance heated tubes to maximize air contact with heated metal.

3.2. WTSM Development. Mathematical models of the wind tunnel process are very complicated because they involve viscous effects and distributed characteristics. In this paper, a nonlinear mathematical model of a BSWT based on isentropic relation was developed in Simulink software environment as shown in Figure 3.

The wind tunnel model is constructed with a component approach for ease of modification and replacement with different tunnel components. The WTSM includes some component modules such as storage tank, control valve, heater, plenum pressure, nozzle, and test section.

\section{Fuzzy Logic Controller for the Plenum Temperature}

The control objective is to provide the plenum chamber temperature desired by the researcher performing tests in the wind tunnel. The application of proportional-integralderivative (PID) control loops to the temperature processes in the system results in unacceptable control with respect to operation within system temperature constraints and regulation of the controlled process at the desired temperature. A PID control loop is unable to reasonably handle the long delay time in temperature response associated with air flow through long lengths of metal piping which absorb thermal energy. The recent application of a FLC provides appropriate control of the heaters to obtain the desired plenum chamber temperature.

A FLC utilizes FL to convert linguistic information based on expert knowledge into an automatic control strategy. In order to use the FL for control purposes, a front-end "fuzzifier" and a rear-end "defuzzifier" are added to the usual input-output data set. A FLC commonly consists of four sections: rules, fuzzifier, inference engine, and defuzzifier. Once the rule has been established, the controller can be considered as a nonlinear mapping from the input to the output [12]. The block diagram of the generalized indistinct controller is presented in Figure 4.

The designed FLC would determine the amount of heater thermal power over its transient operation. The FLC and the available WTSM constitute a closed loop which is shown in Figure 5.

The first input of the fuzzy controller is the temperature error (Error). The second input is the first input variations over time (Error Rate). The defined membership functions (MFs) for the inputs are shown in Figure 6. The FLC output is heater power over time. The defined fuzzy MFs for the FLC output are shown in Figure 7.

Conventionally, fuzzy rules are established by a combination of knowledge, experience, and observation and may thus not be optimal. Additionally, in spite of efforts to formalize a development standard for fuzzy controllers, fine tuning its performance is still a matter of trial and error $[13,14]$. 


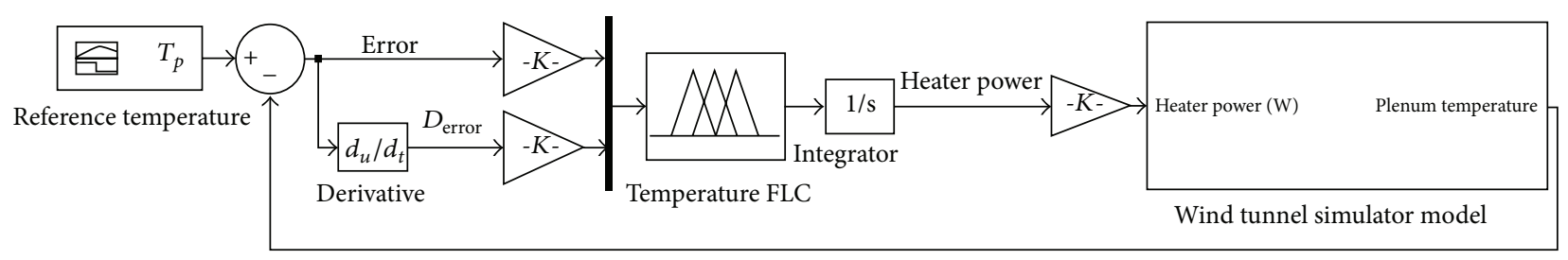

Actual plenum temperature

FIGURE 5: Layout of the wind tunnel model and the temperature controller.

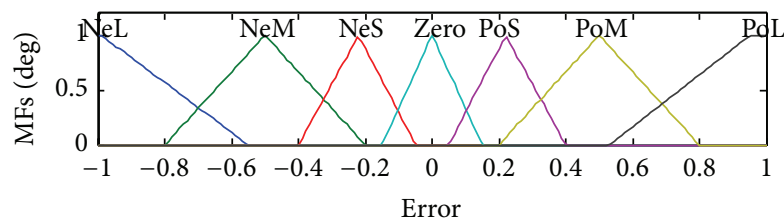

(a)

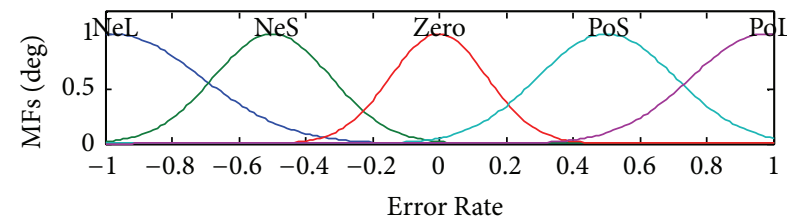

(b)

FIgURE 6: The defined membership functions for (a) Error and (b) Error Rate.

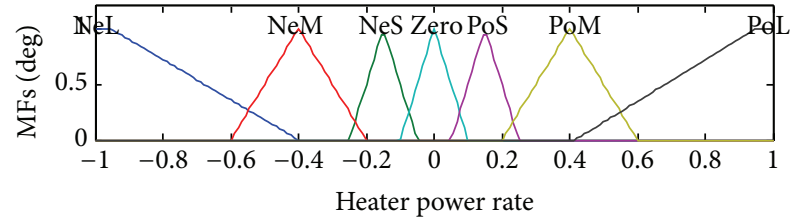

FIGURE 7: Heater power rate membership functions (FLC output).

TABLE 1: The fuzzy rules list.

\begin{tabular}{lccccc}
\hline \multirow{2}{*}{ Heater power rate } & \multicolumn{5}{c}{ Error Rate } \\
& NeL & NeS & Zero & PoS & PoL \\
\hline Error & & & & & \\
NeL & Zero & NeM & NeL & NeL & NeL \\
NeM & PoL & Zero & NeS & NeL & NeL \\
NeS & PoM & PoS & Zero & NeM & NeL \\
Zero & PoM & PoS & Zero & NeS & NeM \\
PoS & PoL & PoM & Zero & NeS & NeM \\
PoM & PoL & PoL & PoS & Zero & NeL \\
PoL & PoL & PoL & PoL & PoM & Zero \\
\hline
\end{tabular}

The fuzzy rules list is presented in Table 1. For instance, one of the table entries is the equivalent of "if Error is PositiveLarge and Error Rate is Zero then Heater Power Rate is Positive Large."

The defuzzification process takes place after the generation of the fuzzy control signals is completed using the inference mechanism. The resulting fuzzy set must be converted to a quantity which would be sent to the process regulating valve as a control signal. In this part, the inference results of all activated logic rules are synthesized into crisp output for making a decision. In this research study, the logic AND has been implemented with the minimum operator, and the defuzzification method is based on bisector area.

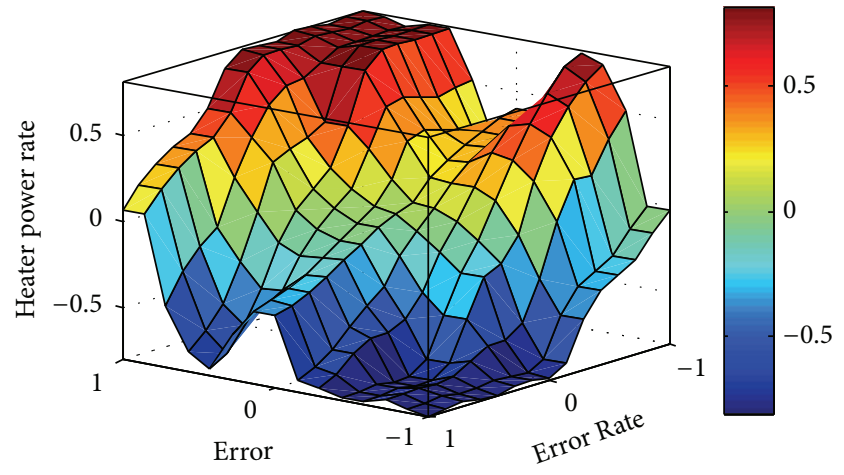

FIGURE 8: Control surface output of the FLC.

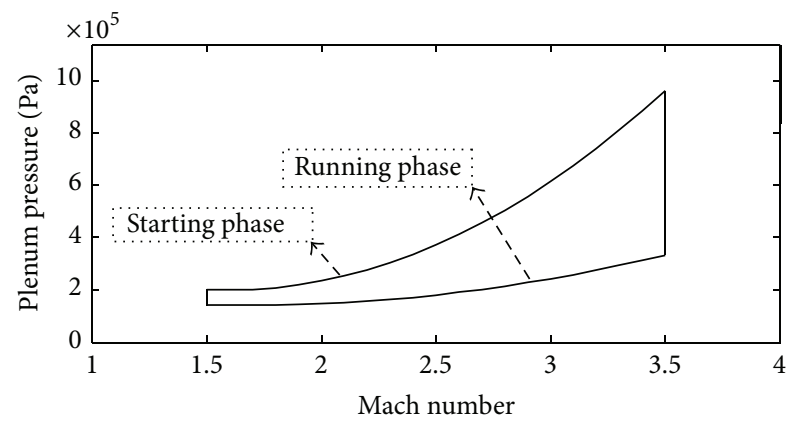

FIGURE 9: The tests range for the proposed BSWT.

The variation of heater power rate versus the two controller inputs is depicted in Figure 8.

By designing the controller, the influence of controller parameters on wind tunnel should be examined in more detail. So it would be essential to simulate the wind tunnel and controller simultaneously. 


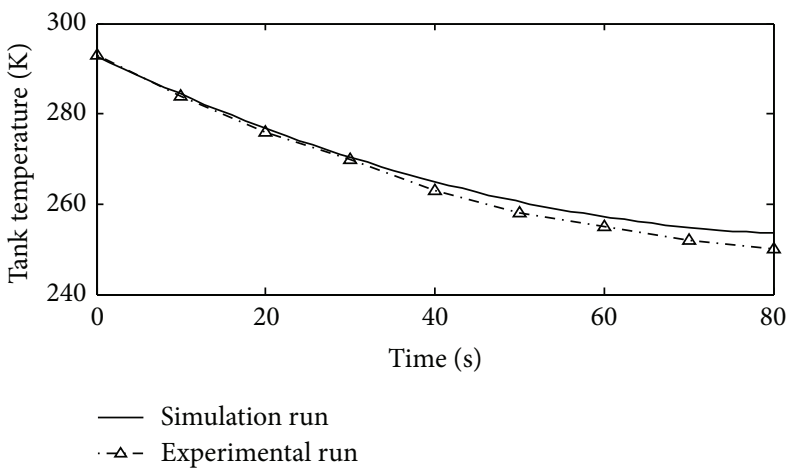

FIGURE 10: Temperature variation for a Mach 2.5 run.

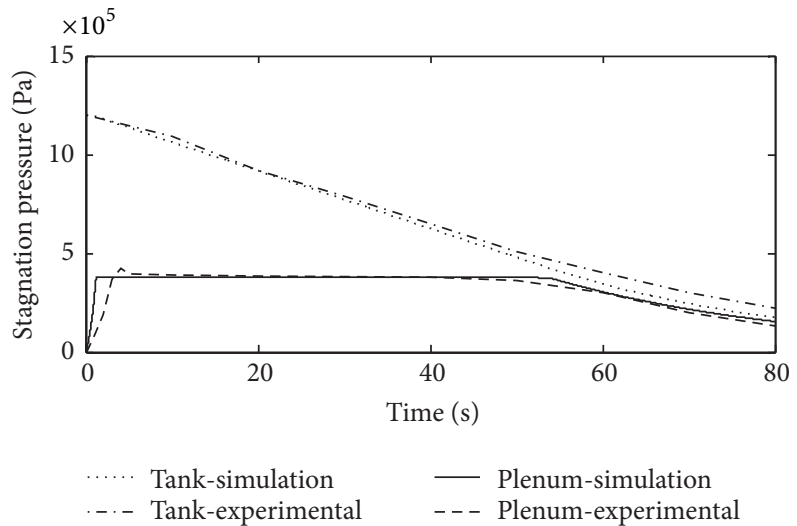

(a)

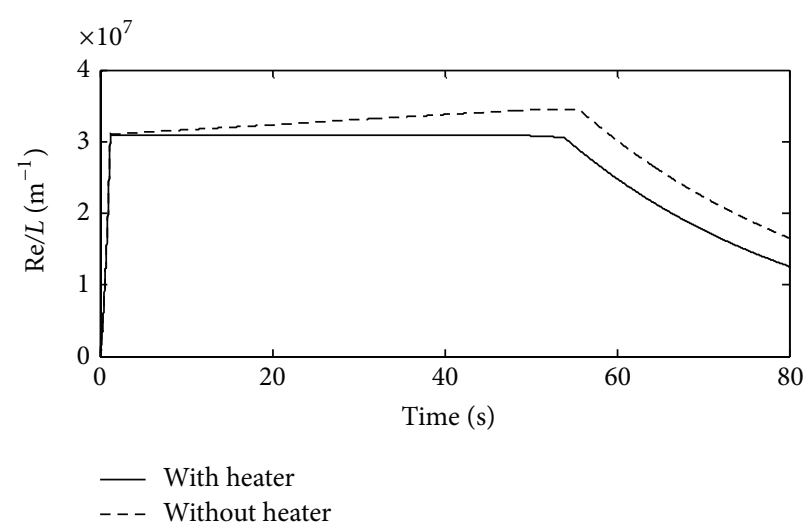

(b)

FiguRE 11: Simulation results for a Mach 2.5 run: (a) plenum and storage tank pressures with experimental results and (b) Reynolds number in the test section.

\section{Simulation Results}

This paper is focused on the tunnel performance for Mach 2.5 blowdown run. The tunnel operational map (Figure 9), which is based on the tests data, is used to select the proper pressure controller setpoint for the proposed Mach number in the test section. It is previously noted that the stagnation temperature drops according to the polytropic process in the storage tank. In this regard, Figure 10 shows the temperature drops during the wind tunnel run without heater for a Mach 2.5 run [1].

The wind tunnel simulation results with temperature controller for Mach 2.5 are presented in Figure 11. It should be noted that the reference temperature for heater controller is considered to be equal to $300 \mathrm{~K}$. Also experimental verification has been carried out for supersonic conditions to show the accuracy of the fuzzy logic applied to the BSWT.

Figure 11(a) shows plenum and tank stagnation pressures for a Mach 2.5 run. Also the figure shows the pressure variation in comparison with experimental run. By the way, Figure 11(b) shows that using heater is caused to maintain the Reynolds number in the test section during the tunnel operation.

Also the valve opening and flow rate variations for a Mach 2.5 blowdown run are presented in Figures 12(a) and 12(b).
According to Figure 12(a), after 54 seconds of tunnel operation, the control valve opening reaches its maximum opening condition. In this situation, the plenum pressure and Reynolds number are dropped suddenly.

Plenum temperature and heater power variations are presented in Figures 12(c) and 12(d). According to the figures, plenum temperature is kept as close as the reference temperature $(300 \mathrm{~K})$ with the lowest overshoot, settling time, and steady state error.

\section{Conclusion}

In this paper, first, a nonlinear mathematical model of special supersonic wind tunnel is developed in Simulink software environment. Then, a fuzzy logic controller system is developed to control the plenum stagnation temperature. Finally, the simulation results for Mach 2.5 blowdown run in comparison with the experimental results are presented. The stagnation temperature affects the Reynolds number and the Mach number of a blowdown supersonic test. For example, in the proposed wind tunnel, the Reynolds number increases 13.16 percent from $30.8 \times 10^{6} / \mathrm{m}$ at Mach 2.5 when the stagnation temperature drops from 290 to $260 \mathrm{~K}$. In this paper, the temperature drop is suppressed by installing heater 


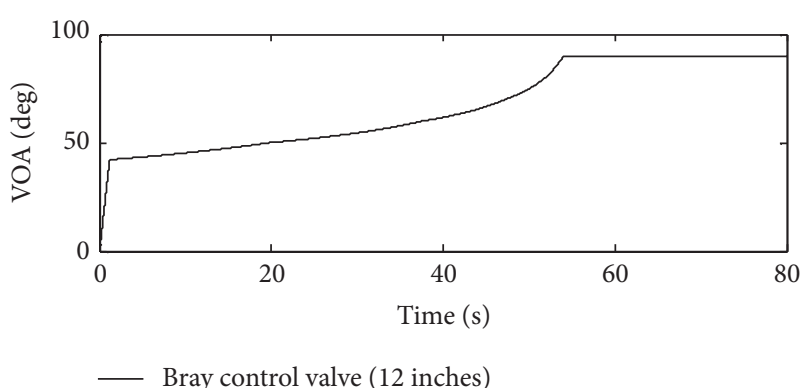

(a)

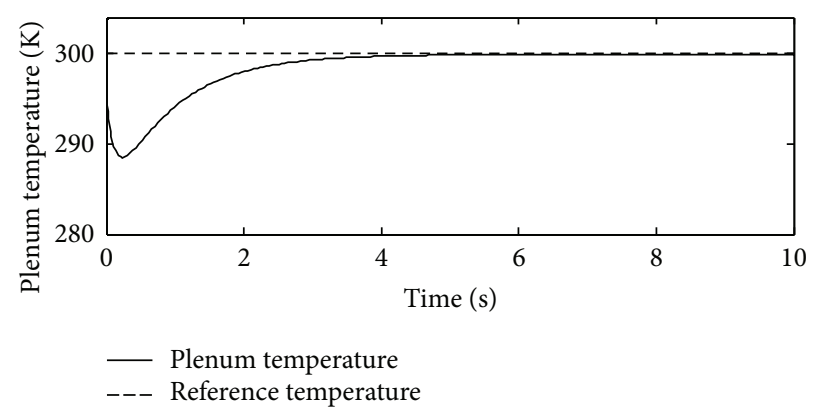

(c)

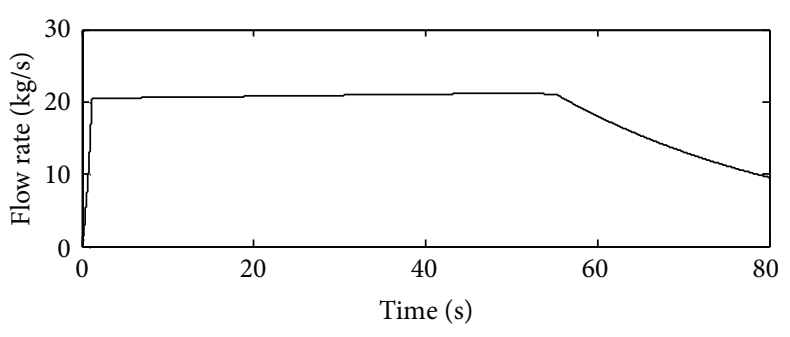

(b)

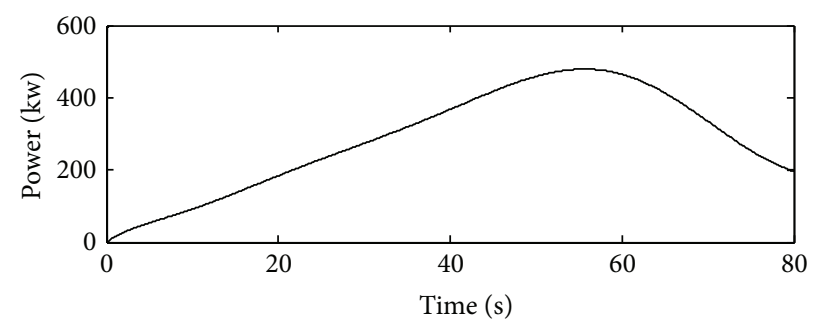

(d)

Figure 12: Simulation results for a Mach 2.5 run: (a) valve opening angle (VOA) function, (b) valve flow rate, (c) plenum stagnation temperature, and (d) heater power variation during the tunnel run.

and temperature controller upstream of the plenum chamber to maintain a constant Reynolds number with keeping the stagnation pressure constant. In this way, the Error in the heater performance during the run is minimized with the control program for the wind tunnel facility characteristics. The new intelligent control system leads to a control response with the lowest overshoot, settling time, and steady state error.

\section{Conflict of Interests}

The authors declare that there is no conflict of interests regarding the publication of this paper.

\section{References}

[1] A. Nazarian Shahrbabaki, M. Bazazzadeh, A. Shahriari, and M. D. Manshadi, "Intelligent controller design for a blowdown supersonic wind tunnel," SERSC International Journal of Control and Automation, vol. 7, pp. 409-426, 2014.

[2] F. K. Lu, D. R. Wilson, and J. Matsumoto, "Rapid valve opening technique for supersonic blowdown tunnel," Experimental Thermal and Fluid Science, vol. 33, no. 3, pp. 551-554, 2009.

[3] C. R. Nott, S. M. Ölçmen, D. R. Lewis, and K. Williams, "Supersonic, variable-throat, blow-down wind tunnel control using genetic algorithms, neural networks, and gain scheduled PID," Applied Intelligence, vol. 29, no. 1, pp. 79-89, 2008.

[4] S. H. Rajani, M. K. Bindu, and N. Usha, "Stability analysis and temperature effect on the settling chamber pressure of a hypersonic wind tunnel," in Proceedings of the IEEE International Conference on Computational Intelligence and Computing Research (ICCIC '12), 2012.
[5] D.-S. Hwang and P.-L. Hsu, "A robust controller design for supersonic intermittent blowdown-type windtunnels," Aeronautical Journal, vol. 102, no. 1013, pp. 161-169, 1998.

[6] L. A. Zadeh, G. J. Klir, and B. Yuan, Fuzzy Sets, Fuzzy Logic, Fuzzy Systems, World Scientific Publishing, Hackensack, NJ, USA, 1996.

[7] P. J. King and E. H. Mamdani, "The application of fuzzy control systems to industrial processes," Automatica, vol. 13, no. 3, pp. 235-242, 1977.

[8] A. Pope and K. L. Goin, High-Speed Wind Tunnel Testing, John Wiley \& Sons, New York, NY, USA, 1965.

[9] L. Biagioni, F. Scortecci, and F. Paganucci, "Development of pulsed arc heater for small hypersonic high-enthalpy wind tunnel," Journal of Spacecraft and Rockets, vol. 36, no. 5, pp. 704710, 1999.

[10] Fisher Controls International, Control Valve Handbook, Fisher International Company, Marshalltown, Ia, USA, 2nd edition, 2005.

[11] L. Driskell, Control-Valve Selection and Sizing, Instrument Society of America, Research Triangle Park, NC, USA, 1st edition, 1983.

[12] J. H. Lilly, Fuzzy Control and Identification, John Wiley \& Sons, New York, NY, USA, 2010.

[13] D. Driankov, H. Hellendoorn, and M. Reinfrank, An Introduction to Fuzzy Control, Springer, Berlin, Germany, 2nd edition, 1996.

[14] K. M. Passino and S. Yurkovich, Fuzzy Control, Addison-Wesley, San Francisco, Calif, USA, 1998. 

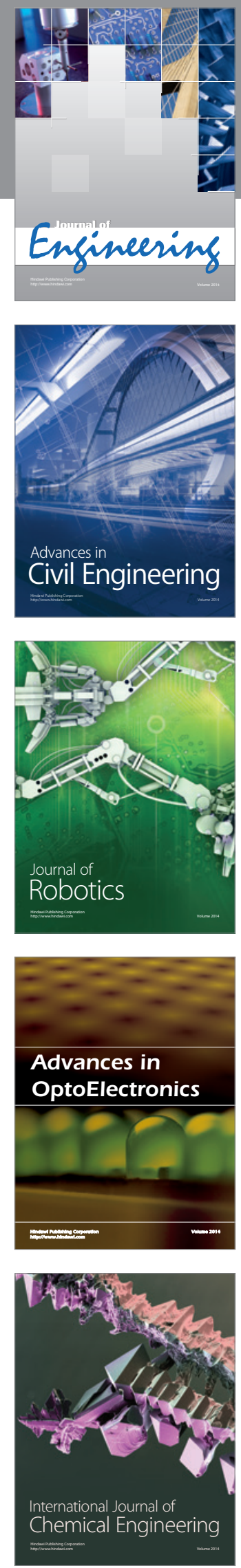

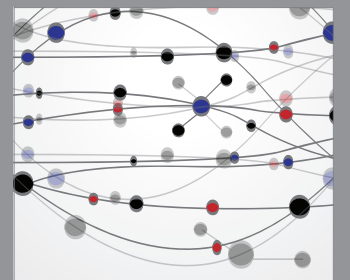

The Scientific World Journal
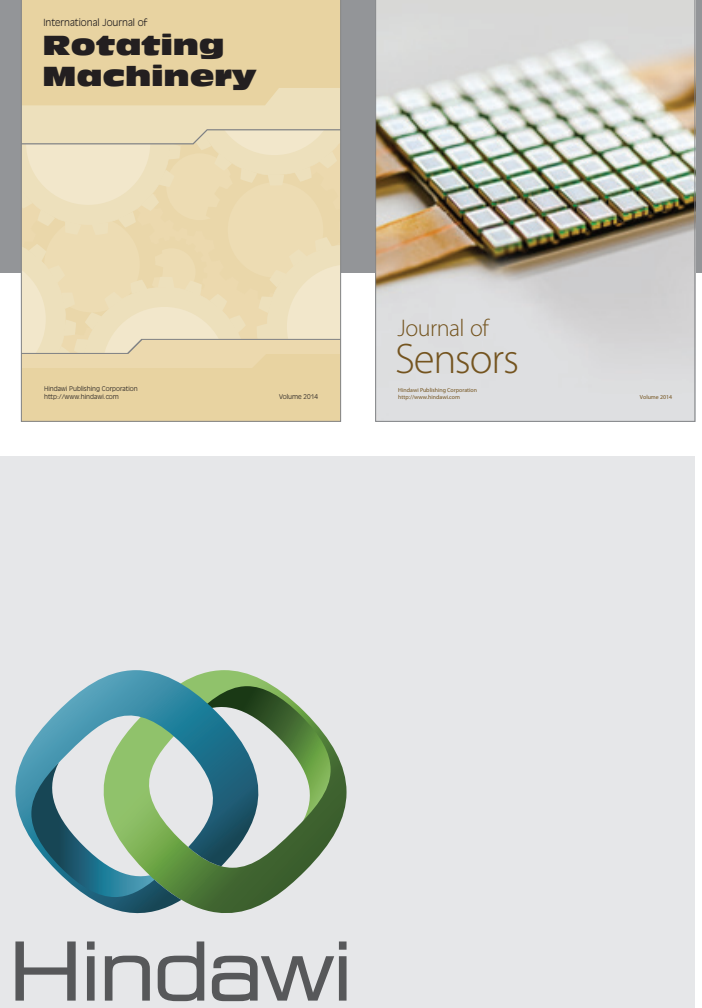

Submit your manuscripts at http://www.hindawi.com
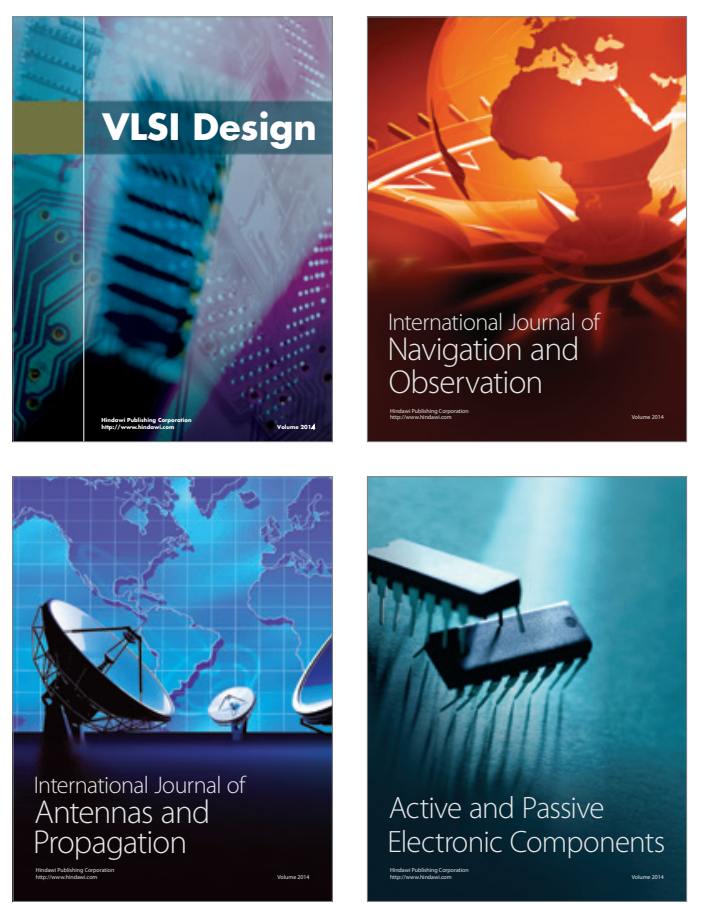
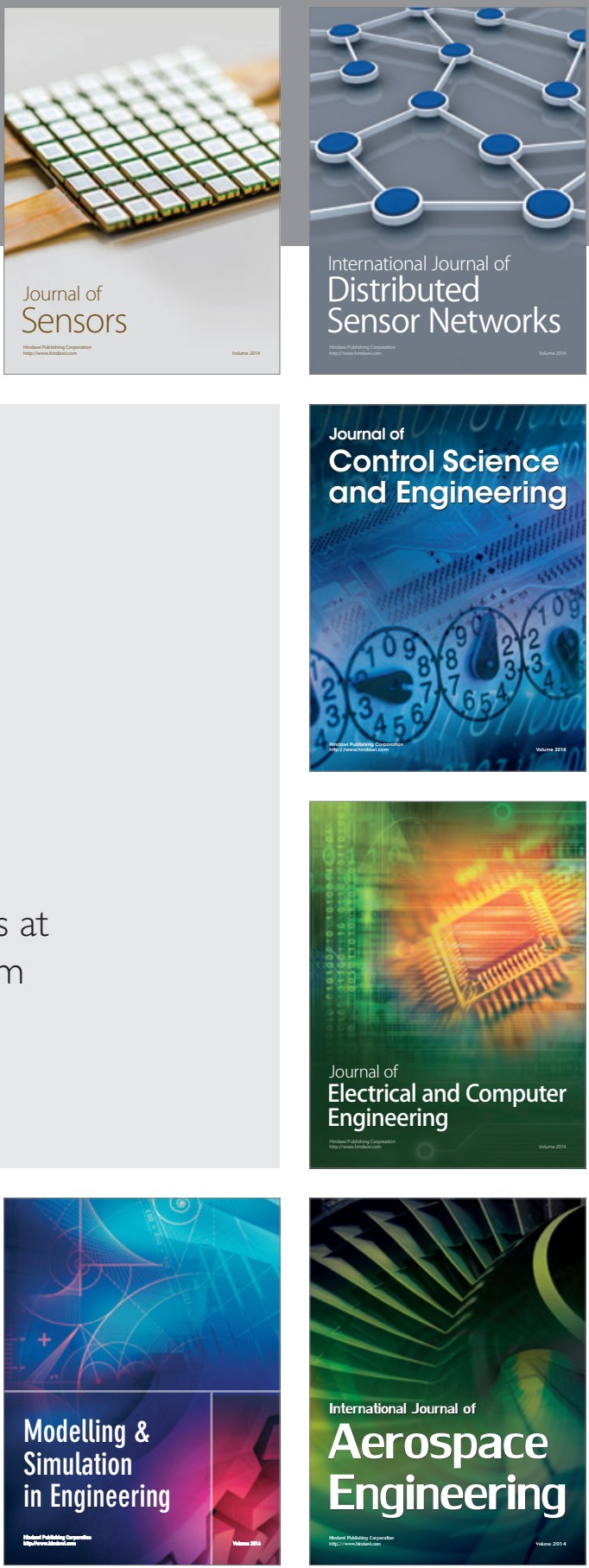

Journal of

Control Science

and Engineering
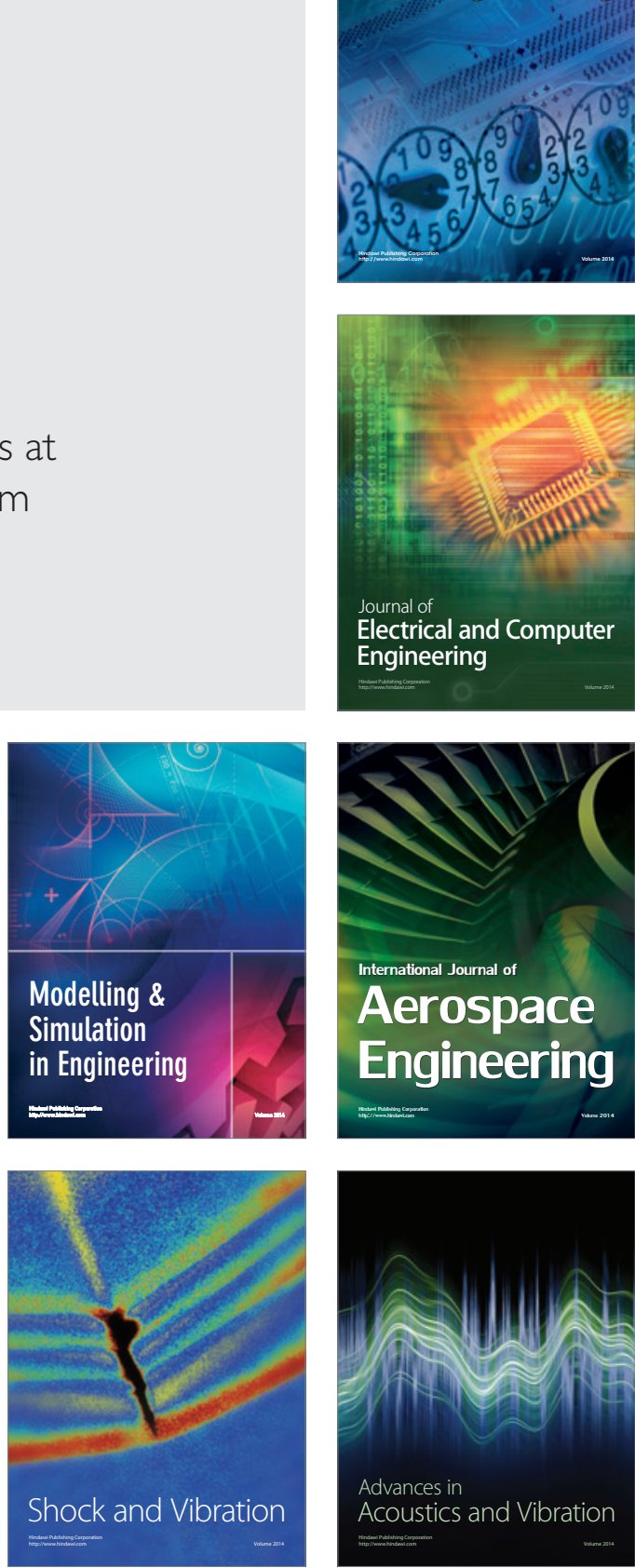